\title{
Effectiveness of Selected Reaction Monitoring for rapid assay of Cypermethrin Residue in Perilla Leaves
}

\author{
Noriyasu Niimura \\ DATUM Solution Business Operations, JEOL Ltd., Tokyo, Japan \\ E-mail: niimura@jeol.co.jp \\ Received May 20, 2011; revised June 14, 2011; accepted June 25, 2011
}

\begin{abstract}
Many kinds of pesticides have been developed and used to yield a good harvest but the residues in agricultural products cause health problems. It is important to keep watch on these residues by using adequate methods of analysis. Pretreatment such as gel permeation chromatography (GPC) or column chromatography is often needed for the quantitative analysis of pesticide in agricultural products by conventional methods such as gas chromatography/low resolving power mass spectrometry (GC/LRMS). However, these pretreatments need a lot of work and take time. New methods saving the necessity of these pretreatments have been desired. We have applied selected reaction monitoring (SRM) to quantitatively determine cypermethrin residues in Perilla frutescens samples and compared the results with LRMS and HRMS in SIM mode. A background peak caused by the matrix overlapped the cypermethrin peak in the analysis using LRMS. SRM and HRMS in SIM mode provided chromatograms without matrix interference. The high selectivity of the product ion $(\mathrm{m} / \mathrm{z}$ 127) produced from precursor ion $(\mathrm{m} / \mathrm{z} 163)$ isolated the target peaks from the matrix peaks when using SRM. This method eliminates the pretreatment step, thus saving time and simplify ing the analytical process.
\end{abstract}

Keywords: Pesticide Residue, Cypermethrin, Perilla Frutescens, Selected Reaction Monitoring, high Resolving Power mass Spectrometry

\section{Introduction}

Many kinds of pesticides have been used for the control of harmful insects in agriculture. These have helped to improve the productivity of crops, but these residues in agricultural products have unfortunately posed a health hazard to the consumers. As for mammalian neurotoxicity, the serious damage to health by prolonged exposure to cypermethrin was reported [1]. Stricter consumer protection laws have been enacted for the control of pesticides in Japan [2]. The legal limit for cypermethrin in Perilla frutescens leaves was set to be less than $6 \mu \mathrm{g} / \mathrm{ml}$. This underscores the need for efficient analytical procedures for pesticide residue detection in agricultural products. Conventional methods are complicated and time consuming, because the sample matrixes extracted from agricultural products are usually very complex [3]. For example, methods using a gas chromatography/low resolving power mass spectrometry (GC/LRMS) or a GC with an electron capture detector (GC-ECD) need pretreatments such as gel permeation chromatography (GPC) or column chromatography to remove matrix interferences [4-9]. A simpler method without the time consuming clean-up and purification procedures is needed for routine analysis. However, the method without pretreatment using a GC/LRMS suffers from lack of accuracy in quantitative analysis, because of the overlapping of the matrix peaks.

In this study, high resolving power mass spectrometry (HRMS) and selected reaction monitoring (SRM) were applied. These methods can isolate target peaks from matrix peaks saving pretreatments. Using these methods, we analyzed cypermethrin added intentionally to the extracts of the leaves of Perilla frutescens and the results were compared with that obtained by using LRMS.

\section{Experiments}

\subsection{Standards and Reagents}

Cypermethrin (purity $>98 \%$ ) was supplied from Dr. 
Ehrenstorfer GmbH (Germany). Acetone, n-hexane, anhydrous sodium sulfate and sodium chloride (pesticide residue analysis grade) were supplied from Wako Pure Chemical Industries (Japan).

\subsection{Extraction}

The leaves of Perilla frutescens $(20 \mathrm{~g})$ were minced and placed into a blender cup. Acetone $(100 \mathrm{ml})$ was added into the blender cup and these were homogenized at $10000 \mathrm{rpm}$ for $2 \mathrm{~min}$. The homogenate was filtered through a filter paper: No. 5A (Advantec Toyo, Japan). The residue was once again homogenized with $100 \mathrm{ml}$ of acetone at 10000 rpm for $2 \mathrm{~min}$. The homogenate was filtered through No. $5 \mathrm{~A}$ filter paper. The filtrate was concentrated to $<30 \mathrm{ml}$ by using a rotary evaporator: RE 801 (Yamato Scientific, Japan) at $40^{\circ} \mathrm{C}$ of bath temperature.

The sodium chloride aqueous solution $(10 \%, 100 \mathrm{ml})$ and $\mathrm{n}$-hexane $(100 \mathrm{ml})$ were added to the extract. The mixture was shaken vigorously for $5 \mathrm{~min}$ and $\mathrm{n}$-hexane $(100 \mathrm{ml})$ was added to the parted aqueous layer. Repeating this procedure, the mixture was extracted two times. The extract was added with anhydrous sodium sulfate $(20 \mathrm{~g})$ and concentrated to $5 \mathrm{ml}$.

\subsection{Samples}

The standard solution of cypermethrin (Mm 415.0742 u) diluted with acetone at $100 \mu \mathrm{g} / \mathrm{ml}$ was used to assign the peaks in mass chromatogram (m/z 163). Aliquots of cypermethrin was added to the extracts of the leaves of Perilla frutescens at $1 \mu \mathrm{g} / \mathrm{ml}$ and measured using HRMS and SRM.

\subsection{GC/MS Condition}

GC/MS was carried out with an Agilent 7890A gas chromatograph (Agilent Technologies, USA) and a twosector mass spectrometer composed of a magnetic sector and an electric sector: JMS-GCmate II (JEOL, Japan). A HP-5MS fused-silica capillary column $(0.25 \mathrm{~mm}$ i.d. $\times$ $30 \mathrm{~m}$, Agilent Technologies, USA) was used for separation. Each sample $(1 \mu \mathrm{l})$ was injected into a GC injector at $250^{\circ} \mathrm{C}$ under splitless condition. The $\mathrm{GC}$ oven was programmed at a constant temperature increase of $10^{\circ} \mathrm{C}$ $/ \mathrm{min}$ from $50^{\circ} \mathrm{C}$ to $200^{\circ} \mathrm{C}$ after holding for $1.5 \mathrm{~min}$ at 50 ${ }^{\circ} \mathrm{C}$ followed by $5^{\circ} \mathrm{C} / \mathrm{min}$ increase from $200^{\circ} \mathrm{C}$ to $300^{\circ} \mathrm{C}$. Electron ionization with $70 \mathrm{eV}$ of ionization energy and $210^{\circ} \mathrm{C}$ of ion source temperature was adopted on all MS analyses. LRMS in scan mode was carried out with a mass resolving power of 500 and a scan range of $\mathrm{m} / \mathrm{z}$ 50-500 to analyze the standard solution of cypermethrin diluted with acetone $(100 \mu \mathrm{g} / \mathrm{ml})$. HRMS in scan mode was carried out with a mass resolving power of 3500 and a scan range of m/z 140 - 185 to analyze the accurate mass of the fragment ion $\mathrm{m} / \mathrm{z} 163$ detected as the base peak in the LRMS. Perfluorokerosene (PFK) was simultaneously analyzed as an internal reference to correct a mass drift. LRMS in selected ion monitoring (SIM) mode was carried out monitoring $\mathrm{m} / \mathrm{z} 163.0076$ with a mass resolving power of 500. HRMS applied SIM mode was carried out monitoring $\mathrm{m} / \mathrm{z} 163.0076$ with a mass resolving power of 3500 . SRM was also performed with the instrument, which is the BE geometry mass spectrometer, with the dissociation occurring in reaction region, prior to the magnetic sector $[10,11]$. The monitored reaction was $\mathrm{m} / \mathrm{z} 163 \rightarrow 127$, which was determined by applying a linked scan MS at constant B/E of m/z 163 (B and $\mathrm{E}$ are magnetic and electric sector field strength, respectively).

\section{Results and Discussion}

\subsection{LRMS in scan Mode (Peak Assignment)}

The chromatogram of the cypermethrin standard solution $(100 \mu \mathrm{g} / \mathrm{ml})$ obtained by GC/LRMS in scan mode is shown in Figure 1. Four peaks (peak \# 1-4) attributed to the isomers of cypermethrin were detected at retention times of $30.87,31.06,31.20$ and $31.28 \mathrm{~min}$. The ratios of respective peak areas were 26.2, 29.1, 20.2 and $24.5 \%$. The 4 isomers of cypermethrin present very similar mass spectra and in Figure 2 is shown the mass spectrum of peak \#1 as an example. Figure 3 shows the assignment of the molecular ion and the base peak ion into the mass spectrum. The molecular ion of cypermethrin was detected at $\mathrm{m} / \mathrm{z} 415$, the isotopic molecular ion attributed to ${ }^{37} \mathrm{Cl}$ corresponds to $\mathrm{m} / \mathrm{z} 417$, the base peak $\left[{ }^{12} \mathrm{C}_{7}{ }^{1} \mathrm{H}\right.$ $\left.{ }_{9}^{35} \mathrm{Cl}_{2}\right]^{+}$was detected at $\mathrm{m} / \mathrm{z} 163$ and the isotopic fragment ion $\left[{ }^{12} \mathrm{C}_{7}{ }^{1} \mathrm{H}_{9}{ }^{35} \mathrm{Cl}^{37} \mathrm{Cl}\right]^{+}$was detected at $\mathrm{m} / \mathrm{z} 165$ showing about $64 \%$ peak intensity of the base peak. Cypermethrin isomers were reported to be detected as four peaks [9]. These previous reports support the results in this study.

\subsection{HRMS in scan Mode}

Using HLMS in scan mode, the accurately measured mass of the fragment ion $\left[{ }^{12} \mathrm{C}_{7}{ }^{1} \mathrm{H}_{9}{ }^{35} \mathrm{Cl}_{2}\right]^{+}$was determined as $163.0072 \mathrm{u}$. The calculated mass of the fragment ion was $163.0076 \mathrm{u}$. The difference between the measured mass and the calculated mass was $0.0004 \mathrm{u}$.

\subsection{LRMS in SIM Mode}

The chromatogram of perilla leaves extract spiked with cypermethrin at $1 \mu \mathrm{g} / \mathrm{ml}$ is shown in Figure 4. A background peak caused by the matrix overlapped with the 
cypermethrin peak \#1. The two retention times were almost the same, so that it was difficult to separate these two peaks modifying the GC condition. The peak area ratios of peak \#1-4 were 40.0, 22.7, 18.5 and 18.8\%, respectively in these conditions. The peak area ratios were significantly different from those of the standard solution; hence HRMS or SRM will be needed for reliable quantitative results.

\subsection{HRMS in SIM mode}

The chromatogram of perilla leaves spiked with cypermethrin at $1 \mu \mathrm{g} / \mathrm{ml}$ is shown in Figure 5. The peak area ratios of peak \#1-4 were 26.3, 29.0, 20.4 and $24.3 \%$ respectively. These ratios were very close to the ones in the standard solution shown in Figure 1. These results revealed that the background peak caused by the matrix did

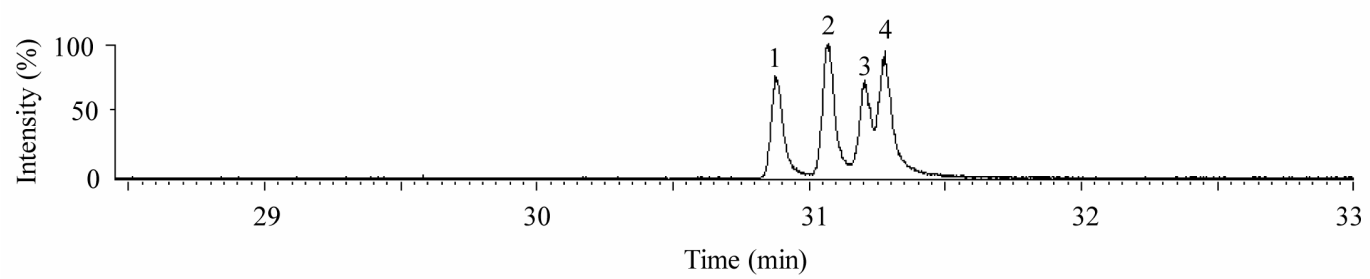

Figure 1. Chromatogram of the cypermethrin standard solution $(100 \mu \mathrm{g} / \mathrm{ml})$ obtained by GC/LRMS in scan mode. 1 . Cypermethrin-1; 2. Cypermethrin-2; 3. Cypermethrin-3; 4. Cypermethrin-4.

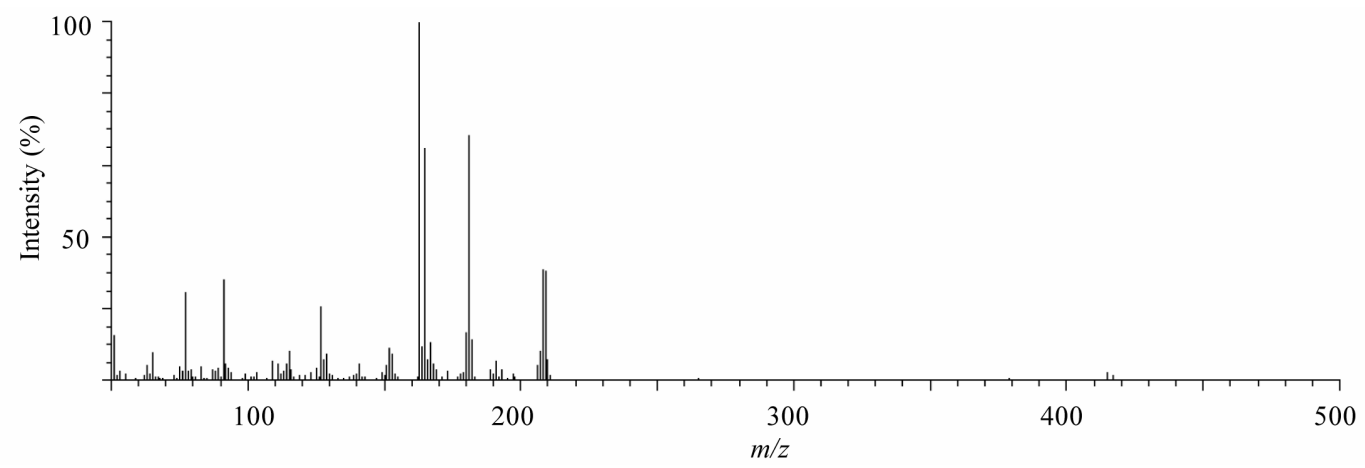

Figure 2. Mass spectrum of the peak \# 1 shown in Figure 1.

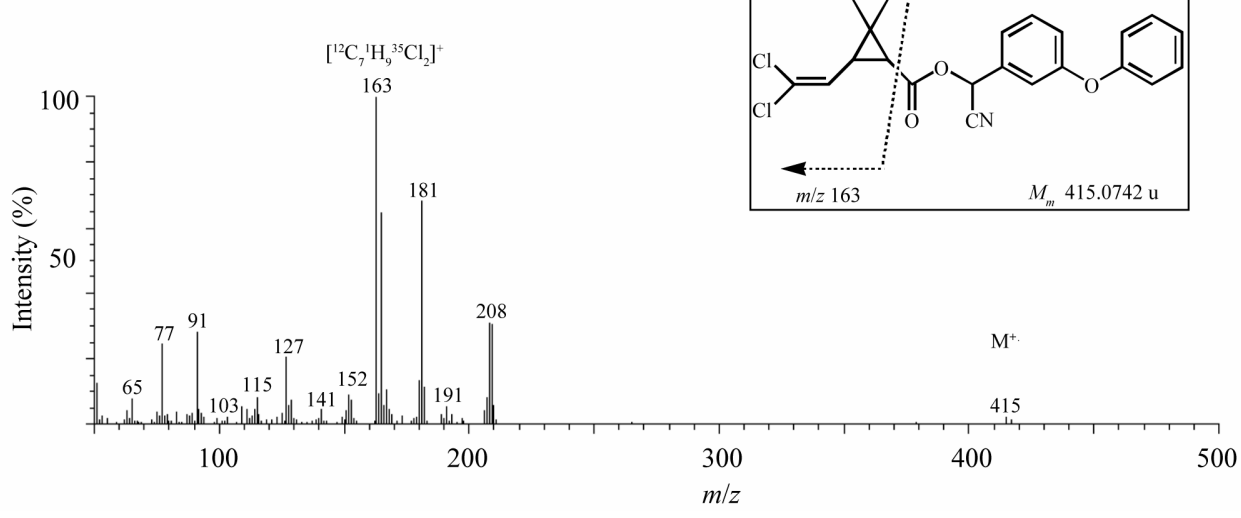

Figure 3. Assignment of the molecular ion $(\mathrm{m} / \mathrm{z} 415)$ and the base peak ion $(\mathrm{m} / \mathrm{z} 163)$.

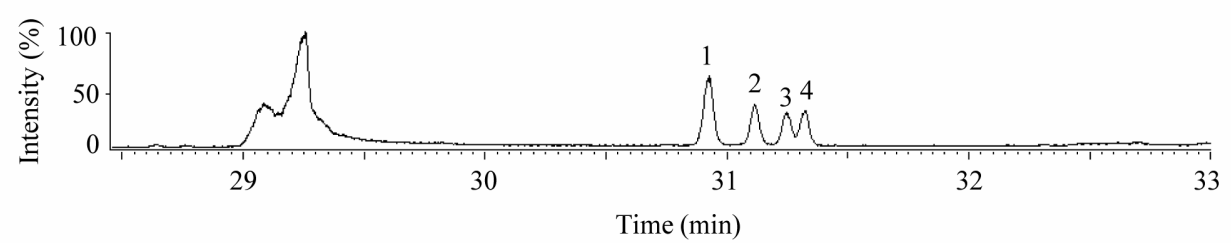

Figure 4. Chromatogram of perilla leaves extract spiked with cypermethrin at $1 \mu \mathrm{g} / \mathrm{ml} \mathrm{obtained} \mathrm{by} \mathrm{GC/LRMS} \mathrm{in} \mathrm{SIM} \mathrm{mode.}$ 


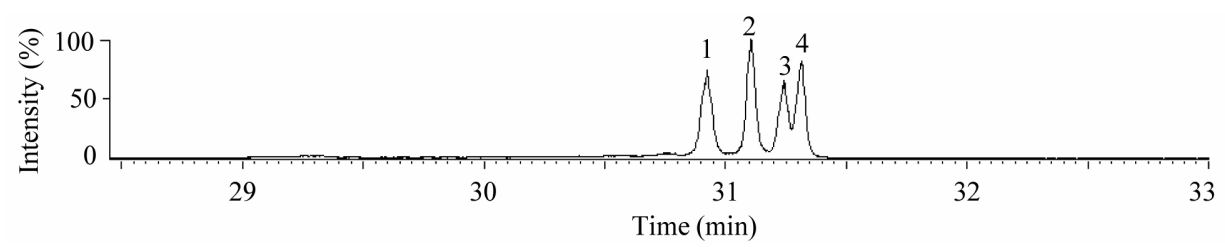

Figure 5. Chromatogram of perilla leaves extract spiked with cypermethrin at $1 \mu \mathrm{g} / \mathrm{ml} \mathrm{obtained} \mathrm{by} \mathrm{GC/HRMS} \mathrm{in} \mathrm{SIM} \mathrm{mode.}$

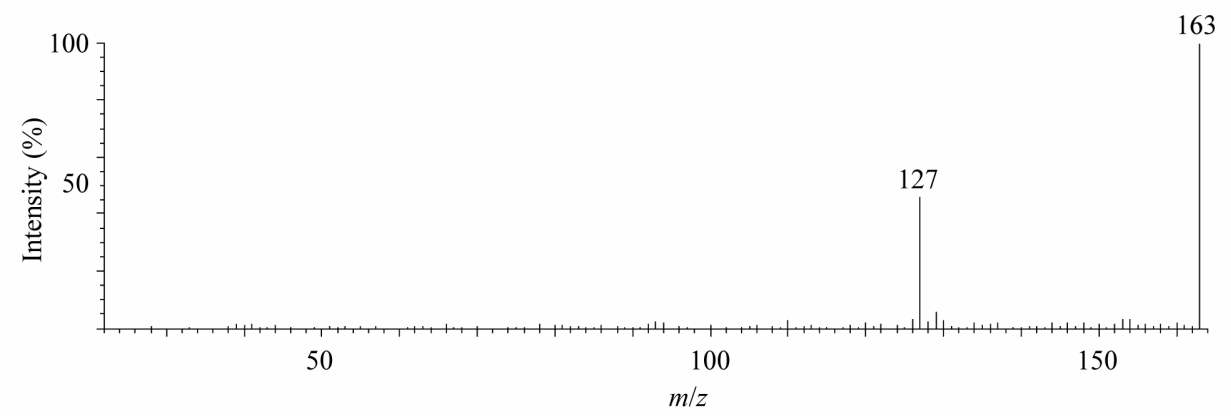

Figure 6. Linked scan mass spectrum at constant $B / E$ of $m / z 163$.

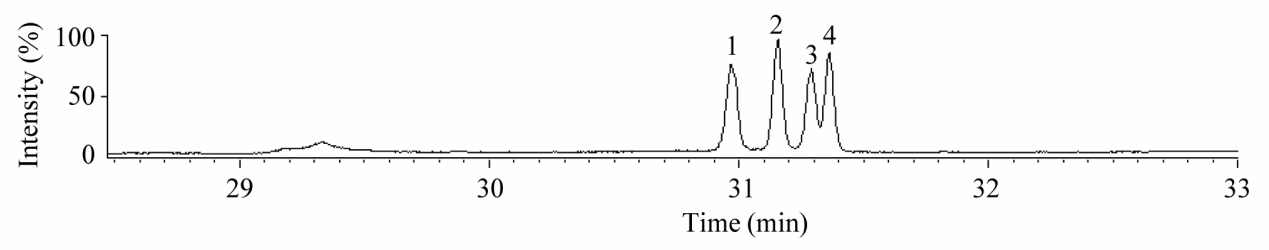

Figure 7. Chromatogram of perilla leaves extract spiked with cypermethrin at $1 \mu \mathrm{g} / \mathrm{ml}$ analyzed by SRM.

not overlap with any peaks of cypermethrin. High selectivity of the fragment ion $(\mathrm{m} / \mathrm{z} 163.0076)$ obtained by using HRMS in SIM mode isolated the target peaks from the matrix peaks. This method thus gave reliable results for quantitative analysis.

\subsection{SRM}

A linked scan MS at constant B/E was performed to determine the efficient reaction for SRM. Figure 6 shows the linked scan mass spectrum at constant B/E of m/z 163 . The precursor ion was detected at $\mathrm{m} / \mathrm{z} 163$ and the product ion was detected at $\mathrm{m} / \mathrm{z} 127$. According to this result, we decided the reaction for SRM as $\mathrm{m} / \mathrm{z} 163 \rightarrow 127$. Figure 7 shows the chromatogram of perilla leaves extract spiked with cypermethrin at $1 \mu \mathrm{g} / \mathrm{ml}$ analyzed by SRM. The peak area ratios of peak \#1-4 were 26.0, 29.3, 20.5 and 24.2\% respectively. These ratios were similar to the result of the standard solution shown in Figure 1 and the HRMS in SIM mode shown in Figure 5. The background peak caused by the matrix did not overlap any peaks of cypermethrin in the same way as the result of HRMS in SIM mode. The high selectivity of the product ion $(\mathrm{m} / \mathrm{z} 127)$ produced from precursor ion $(\mathrm{m} / \mathrm{z} 163)$ isolated the target peaks from the matrix peaks. This method thus gave reliable results for quantitative analysis.

\section{Conclusions}

The SRM process employed in this work led to the isolation of cypermethrin peaks from the matrix without the GPC or column chromatography pretreatments. The peak area ratios of the cypermethrin mass chromatogram $(\mathrm{m} / \mathrm{z}$ $163 \rightarrow 127)$ are similar to those obtained for the standard solution and HRMS in SIM mode. SRM may thus have potential application for rapid assay of other pesticide residues common in agricultural products. That is the subject of our ongoing investigation.

\section{References}

[1] European Food Safety Authority, "Conclusion on Pesticide Peer Review," EFSA Scientific Report, Vol. 196, 2008, pp. 1-119196 (2008) 2.

[2] M. Okihashi, H. Obana, S. Hori, T. Nishimune, "Development of Simultaneous Analysis for Organonitrogen and Pyrethroid Pesticides with GC/MS," Shokueishi, Vol. 35, No. 3, 1994, 258-261. 
[3] Ch. Lentza-Rizos, E. J. Avramides and E. Visi, "Determination of Residues of Endosulfan and Five Pyrethroid Insecticides in Virgin Olive Oil Using Gas Chromatography with Electron-capture Detection," Journal of Chromatography A, Vol. 921, No. 2, 2001, pp. 297-304. doi:10.1016/S0021-9673(01)00874-3

[4] Y. Chatani and M. Komatsu, "Studies on Simultaneous Determination of Pesticide Residues in Tabacco Leaf by GC/MS," Kyouto-Fu Hoken-Kan-kyou-Kenkyujo Nenpou, Vol.45, 2000, pp. 12-15.

[5] J. Cai, B. Z. Liu, X. L. Zhu and Q. D. Su, "Determination of Pyrethroid Residues in Tobacco and Cigarette Smoke by Capillary Gas Chromatography," Journal of Chromatography A, Vol. 964, No. 1-2, 2002, pp. 205-211. doi:10.1016/S0021-9673(02)00586-1

[6] C. Ferrer, M. J. Gomez, J. F. Garcia-Reyes, I. Ferrer, E. M. Thurman and A. R. Fernandes-Alba, "Determination of Pesticide Residues in Olives and Olive Oil by Matrix Solid-Phase Dispersion Followed by Gas Chromatography/Mass Spectrometry and Liquid Chromatography/Tandem Mass Spectrometry," Journal of Chromatography A, Vol. 1069, No. 2, 2005, pp. 183194. doi:10.1016/j.chroma.2005.02.015

[7] I. R. Pizzutti, R. J. J. Vreuls, A. de Kok, R. Roehrs, S.
Martel, C. A. Friggi and R. Zanella, "Design of a Compressed Air Modulator to Be Used in Comprehensive Multidimensional Gas Chromatography and Its Application in the Determination of Pesticide Residues in Grapes," Journal of Chromatography A, Vol. 1216, No. 15, 2009, pp. 3305-3311. doi:10.1016/j.chroma.2009.01.088

[8] A. Di Muccio, D. A. Barbini, T. Generali, P. Pelosi, A. Ausili, F. Vergori and I. Camoni, "Clean-up of Aqueous Acetone Vegetable Extracts by Solid-Matrix Partition for Pyrethroid Residue Determination by Gas Chromatography-Electron-capture Detection," Journal of Chromatography A, Vol. 765, No. 1, 1997, pp. 39-49.

[9] Y. Nakamura, Y. Tonogai, Y. Tsumura and Y. Ito, "Determination of pyrethroid residues in vegetables, fruits, grains, beans and green tea leaves: applications to pyrethroid residue monitoring studies," J. AOAC International, Vol. 76, No. 6, 1993, pp. 1348-1361.

[10] K. L. Busch, G. L. Glish and S. A. McLuckey, "Mass Spectrometry/Mass Spectrometry: Techniques and Applications of Tandem Mass Spectrometry," VCH, New York, 1988.

[11] E. D. Hoffmann and V. Stroobant, "Mass Spectrometry: Principle and Applications," 3rd Edition, John Wiley \& Sons Ltd, Chichester, 2007. 